The relation between role constructions and adjustment among stepfathers.

By: Mark A. Fine, Lawrence H. Ganog and Marilyn Coleman

Fine, M. A., Ganong, L. G., \& Coleman, M. (1997). The relation between role constructions and adjustment among stepfathers. Journal of Family Issues, 18(5), 503-525. doi:

$10.1177 / 019251397018005003$

Made available courtesy of SAGE Publications: http://jfi.sagepub.com/content/18/5/503

***Reprinted with permission. No further reproduction is authorized without written permission from SAGE Publications. This version of the document is not the version of record. Figures and/or pictures may be missing from this format of the document. $* * *$

\begin{abstract}
:
The purpose of this study was to assess the relations between stepfathers' constructions of their role as stepfathers and several dimensions of their adjustment. Thirty-nine stepfathers who resided with stepchildren between the ages of 10 and 18 completed a series of self-report measures assessing their perceptions of the stepfather role and their perceived adjustment in several individual, stepfather, marital, and family domains. Positive stepfather outcomes were related to (a) stepfathers' perceptions that they frequently engage in parenting behaviors and that they should engage in these behaviors; (b) small discrepancies between perceived role behavior and standards of how one should behave as a stepfather, particularly with respect to the warmth dimension of parenting; and (c) role clarity. Implications for theory modification and future research are discussed.
\end{abstract}

Keywords: parenting | stepfathers | marriage | family issues | families

\title{
Article:
}

The purpose of this study was to assess the relations between stepfathers' constructions of their role as stepfathers and several dimensions of their adjustment. Thirty-nine stepfathers who resided with stepchildren between the ages of 10 and 18 completed a series of self-report measures assessing their perceptions of the stepfather role and their perceived adjustment in several individual, stepfather, marital, and family domains. Positive stepfather outcomes were related to (a) stepfathers' perceptions that they frequently engage in parenting behaviors and that they should engage in these behaviors; (b) small discrepancies between perceived role behavior and standards of how one should behave as a stepfather, particularly with respect to the warmth dimension of parenting; and (c) role clarity. Implications for theory modification and future research am discussed. 
Much of the clinical and theoretical literature on stepfamilies has suggested that how well stepfamily members adjust to their circumstances depends on how issues pertaining to the role of the stepparent are managed (Crosbie-Burnett, 1989; Visher \& Visher, 1988, 1996). In this study, guided by symbolic interaction and self-discrepancy theories, we assess how several aspects of stepfathers' constructions of their role relate to a number of dimensions of their adjustment.

\section{THEORETICAL PERSPECTIVES}

Symbolic interaction theory emphasizes that individuals actively try to derive meanings from their interpersonal interactions and that their behavior is determined by the meanings they assign to their experiences (LaRossa \& Reitzes, 1993; Stryker \& Statham, 1985). Further, these meanings may change over time as individuals have new experiences.

One set of meanings that individuals construct is their notion of a role for a particular social position. According to Rodgers and White (1993), a social role consists of "all the norms attached to a given social position" (p. 234). A norm, in turn, is defined as "a social rule for the behavior of an incumbent of a social position" (p. 232). A role consists of both a cognitive dimension (i.e., a set of rules or expectations for appropriate behavior) and a behavioral dimension (i.e., the extent to which the social rules or expectations are followed in actions). Norms contain both an intrapersonal (i.e., the individual's impression of a social rule) and a social (i.e., rules that are consensually accepted by most members of a society or culture) aspect. In this study, because our underlying conceptual framework (Higgins's, 1987, self-discrepancy theory) focuses on individuals' cognitions pertaining to their roles, we examined the individuals' appraisals of both of these aspects of social norms.

Extending this definition of a social role, we argue that there are two aspects of the cognitive dimension of a role: the content of the role and the clarity of the role. The content of the role refers to beliefs about how the role should be enacted, whereas the clarity of the role refers to individuals' level of certainty that their beliefs about the content are appropriate for the given role. These two cognitive aspects of the social role are conceptually independent. For example, two people may share similar beliefs about the content of a given role, but one person may be quite certain that the beliefs are appropriate, whereas the other person may have substantial doubts about the appropriateness of the beliefs.

The perceived content of the role may be further subdivided according to its source. One source of the content of an individual's perceived role is based on personal standards for behavior. The other source is based on one's sense of how others believe he or she should behave. In Higgins's (1987) self-discrepancy theory, the first dimension is referred to as the "ideal self," whereas the second dimension is referred to as the "ought self" According to this theory, when there is a discrepancy between the "actual self" (i.e., self-reported role behavior) and the ideal self, and this discrepancy is activated (i.e., a stimulus in a particular context prompts the individual to become aware of the discrepancy), individuals will experience dejection-related emotions, such as 
depression, dissatisfaction, and disappointment. By contrast, when there is a discrepancy between the actual self and the ought self, and this discrepancy is activated, individuals will experience agitation-related emotions, such as anxiety and shame. Several studies have supported these basic tenets of the theory (e.g., Higgins, Klein, \& Strauman, 1985; Strauman \& Higgins, 1987), including a recent study that found that, as hypothesized, self-ideal and selfought parental role discrepancies before the birth of a first child predicted dejection-related and agitation-related emotions, respectively, 3 months after becoming a parent (Alexander \& Higgins, 1993). Because it involved fast-time parents, the Alexander and Higgins study may not be generalizable to other types of parents, including stepparents; however, we are unaware of any studies that have tested Higgins's theory with stepparents.

\section{THE STEPPARENT ROLE}

Applying Rodgers and White's (1993) definition of a social role to the stepfamily context, the stepparent role consists of the norms attached to the position of stepparent. Consistent with our extension of this definition stated earlier, the three primary dimensions of the stepparent role of interest in this study were (a) beliefs about how stepparents should behave (the content of the role expectation), whether derived from personal standards (ideal self) or from beliefs about others' standards (ought self); (b) the level of certainty of beliefs about how stepparents should behave (stepparent role clarity); and (c) the behaviors performed to fulfill the role of the stepparent (perceived role behavior). Previous literature has generally not distinguished among these three dimensions of the stepparent role.

Although individuals have multiple roles in their lives (e.g., a man in a stepfather family simultaneously occupies the family positions of husband and stepfather), our focus in this study is solely on constructions of how stepfathers should function in relationships with their stepchildren. Thus, although stepfathers behave in ways that affect a number of individuals, we focused on those behaviors that directly affect stepchildren.

We investigated the stepparent role in relation to two specific types of parenting behaviors-warmth and control--that have been identified as critical determinants of children's development (Lamborn, Mounts, Steinberg, \& Dornbusch, 1991; Maccoby \& Martin, 1983; Steinberg, Dornbusch, \& Brown, 1992). Warmth refers to the extent to which parents support, spend time with, and communicate with their child or adolescent. Control refers to the degree to which parents set and enforce limits and monitor their child's or adolescent's activities.

\section{THE RELATION BETWEEN STEPPARENT ROLE CONSTRUCTIONS AND} ADJUSTMENT

The primary objective of the present study was to assess the relations between both the content and the clarity of the stepparent role and several dimensions of stepfather well-being. Given the symbolic interactionist view that the manner in which roles are constructed pervasively influences family life (LaRossa \& Reitzes, 1993), stepfathers' perceptions of their adjustment 
were examined in multiple overlapping domains: as individuals, as stepfathers, as spouses, and as members of the stepfamily.

The first purpose of this study was to determine the nature of the relation between perceptions of the content of the stepparent role and stepfather adjustment. Previous research on stepfather families with relatively young children early in the remarriage (Bray \& Berger, 1993; Hetherington, 1993) has suggested that the adjustment of units within the stepfamily system is facilitated when the stepfather role is construed as relatively inactive, at least in the early years of the stepfamily. By contrast, Marsiglio (1992) found that more fatherlike perceptions by stepfathers were positively related to the stepfathers' perceived quality of the stepfather-stepchild relationship. This finding may suggest that construing the role of the stepparent as relatively active may be related to their adjustment. In this study, we examined the following aspects of the content of the stepparent role: stepfathers' perceptions of how often parenting behaviors are performed (actual self, hereafter referred to as "self"), standards about how often these behaviors should be performed (ideal self, hereafter referred to as "ideal"), and beliefs about others' standards about how often these behaviors should be performed (ought self, hereafter referred to as "ought"). Given the inconsistent findings from prior research (i.e., adjustment has been found to be related to reports of both inactive and active disciplinary practices), we revisited this issue and posed no hypotheses about how the perceived content of the stepparent role would relate to stepfathers' adjustment in the multiple domains assessed.

The second purpose of this study was to assess the relations between role discrepancies and stepfathers' adjustment. Consistent with Higgins (1987), we assessed two types of stepparent role discrepancies: the discrepancy between stepfathers' perceptions of how often they engage in a series of parenting behaviors (self) and both how often they believe that they should engage in these behaviors (ideal) and how often they believe that others think that they should engage in these behaviors (ought). There is reason to speculate that these discrepancies, because they tap perceptions of the role behavior relative to one's standards or perceptions of others' standards, may be even more potent predictors of stepfather adjustment than the constituent perceptions (self, ideal, and ought) themselves. With respect to the self-ought discrepancy, we argue that this discrepancy is likely to be related to agitation-related emotions, even if one does not personally accept or agree with one's perceptions of others' standards for how he or she should behave in a given role. Perceived deviations from others' perceived standards may still cause anxiety and shame because one still has to interact with those whose standards are perceived to differ from one's own behavior.

Only one known study has examined the relations between role discrepancies and stepparent adjustment. Fine and Kurdek (1994), in a sample of 215 stepfathers and stepmothers recruited from the Stepfamily Association of America, found that discrepancies between standards of how often one should engage in warmth parenting behaviors and perceptions of how often one actually engaged in warmth behaviors were negatively related to satisfaction with stepparenting. Similar discrepancies pertaining to the control dimension of parenting were less strongly related 
to parenting satisfaction. However, because Fine and Kurdek used single items to assess standards and perceived role performance, studied a potentially nonrepresentative group of stepparents, and assessed only one dimension of stepparent adjustment, in the present study, we used multi-item measures of standards and perceived role performance, studied a potentially more representative group of stepfathers (i.e., they were not recruited from a self-help organization), and assessed a wide array of adjustment domains.

Based on self-discrepancy theory, we hypothesized that the self-ideal role discrepancy score would be related to dejection-related emotions and a lack of satisfaction in a number of personal, marital, and family-related domains and that the self-ought role discrepancy score would be related to agitation-related emotions, including anxiety and shame pertaining to the stepparent role. Based on findings from Fine and Kurdek (1994), we expected that discrepancies on the warmth parenting dimension would be more strongly related to stepfather adjustment than would discrepancies on the control dimension.

The final purpose of the present study was to assess the link between perceptions of role clarity and stepfathers' adjustment. There is some evidence that the extent to which the stepparent role is clear is related to stepfathers' adjustment. Kurdek and Fine (1991) found that high levels of stepparent role ambiguity were related to stepfathers' reports of low parenting satisfaction. However, because Kurdek and Fine's results have not been replicated and because they assessed a limited array of adjustment domains, we felt that taking another look at this relation with a larger number of adjustment dimensions was warranted. Consistent with Kurdek and Fine's finding, we predicted that greater role clarity would be positively related to stepfather adjustment.

\section{METHOD}

\section{PARTICIPANTS}

Participants were 39 stepfathers who resided full-time with at least one stepchild between the ages of 10 and 18 years. Most (31) of the participants resided in a medium-sized city in a Midwestern state; the remaining participants were from another medium-sized city (6) or a large city (2) in the same state. Their mean age was 40.1 years (SD = 6.7, range 27 to 54) and 37 (94.9\%) were White. The sample was generally of middle socioeconomic status; the stepfathers' mean number of years of education was 15.4 (SD = 3.1, range 11 to 20); 37 (94.9\%) were employed full-time (more than 35 hours per week), 1 (2.6\%) was employed part-time (less than 35 hours per week), and 1 (2.6\%) did not work outside the home; and their median income was in the $\$ 40,000$ to $\$ 50,000$ range.

The stepfathers had been married to their present spouse for a mean of 5.8 years (SD = 3.8, range .6 to 13 ) and had been living with their present spouse for a mean of 6.0 years (SD $=4.1$, range .8 to 16.5). Of the 39 stepfathers, 31 (79.5\%) had been married before; all of these remarried stepfathers had divorced their former spouse; they had been married to their former spouse for a 
mean of 8.6 years ( $\mathrm{SD}=6.4$, range 1 to 21$)$; and there was a mean of 4.2 years $(\mathrm{SD}=4.3$, range .9 to 24 ) between the final separation from, their former spouse and their current remarriage.

To determine the extent to which our sample of stepfathers was representative of the larger population, we compared our sample on selected demographic characteristics to a sample of stepfathers with minor children living in the home from the National Survey of Families and Households (NSFH) (Sweet, Bumpass, \& Call, 1988). For stepfathers with minor children living in the home in the NSFH data set, their mean age was 34.6 years, educational level was 12.7 years, family income was $\$ 42,900$, and the mean length of their remarriage was 4.8 years. These data suggest that our sample, when compared with a nationally representative sample, was somewhat older, better educated, and had been remarried for a longer period of time. These differences should be considered when interpreting our findings.

\section{PROCEDURE}

As part of a larger study, stepfathers were recruited via several methods, including the following: (a) advertisements were placed in local newspapers, (b) an announcement was placed in payroll envelopes at the university, (c) individuals thought to be stepparents were contacted, and (d) a "snowball" technique was used in which study participants suggested the names of other stepparents. Potential participants were told that the study was designed to examine how stepparents and stepchildren relate to one another, They were asked to call a project telephone number at the university, at which point a brief screening interview was conducted to ensure that the individual was eligible. The criterion for inclusion was that a stepchild between 10 and 18 years of age resided in the same household as the stepparent more than half of the time. If there were two or more stepchildren who met this criterion, the oldest one was selected as the target child and the stepfather was asked to respond to subsequent items with reference to this target stepchild.

In the larger study, there were 7 stepmother respondents and some of the stepparents' spouses and stepchildren also completed self-report instruments; however, only the stepfathers' data are reported in this article because the hypotheses are directly,relevant only to stepparents' constructions of their roles and there were not enough stepmothers to justify their inclusion in the data analyses.

A battery of self-report instruments was individually administered to all eligible stepfathers who consented to participate. For the majority of participants (29, or 74.3\%), the instruments were administered on campus; in the remaining cases, instruments were administered through the mail. As an incentive, stepfathers received \$25 for participating in the study. Because of the nature of our recruitment procedures (e.g., advertising in newspapers and in payroll envelopes), it is not possible to estimate an overall response rate. However, among those who contacted us and whom we initiated contacts with, approximately $90 \%$ agreed to and did participate.

\section{MEASURES}


The series of self-report measures fell into three general categories: (a) role constructions; (b) dejection-related emotions and satisfaction with personal, marital, parental, and family experiences; and (c) agitation-related emotions. We acknowledge that there is some controversy pertaining to whether dejection-related (e.g., depression) and agitation-related (e.g., anxiety) emotions are distinct (Watson \& Kendall, 1989); in this study, we honor this historic distinction between these two broad categories of emotion to test predictions derived from self-discrepancy theory. On all multi-item measures, composite scores were derived by computing the mean of the scores on the relevant items.

Role constructions. Role perceptions and discrepancies were measured by the Stepparent Behavior Inventory (SBI), an instrument developed for this study. Although there are already existing instruments that assessed the frequency of various parenting behaviors (e.g., Weinberger Parenting Inventory; Feldman \& Weinberger, 1994), we felt that they (a) did not assess warmth and control behaviors directly, (b) were too long, or (c) did not readily lend themselves to the development of discrepancy scores (see below).

The SBI consisted of three sections. Each section contained the same set of 18 items, but directions for each section differed (see below). Nine items were selected to tap the warmth dimension of parenting (e.g., "compliment your stepchild," "ask your stepchild how his or her day went") and nine assessed the control parenting dimension (e.g., "know where your stepchild is and whom he or she is with," "make sure that your stepchild does his or her homework").

In the first section, "Self," respondents were asked to "rate how often you actually behave in these ways toward your stepchild" on a 1 (rarely or never) to 7 (extremely often or always) Likert-type scale. In the second section, "Ideal," respondents were asked to "rate how often you personally believe that you should behave in these ways." In the third section, "Ought," respondents were asked to rate "how often you think others believe that you should engage in these behaviors." Cronbach's alphas were .87, .87, and .89 for the self, ideal, and ought 9-item warmth composite scores, respectively; and .88,.86, and .86 for the self, ideal, and ought 9-item control composite scores, respectively. The intercorrelations between the six SBI subscales ranged from .37 to .86, with a mean of .62. Although these intercorrelations are moderate to high in magnitude, they are sufficiently low (the mean correlation of .62 indicates that there was an average of $39 \%$ shared variance between subscales) to justify retaining the separate subscale composite scores.

Although no previous studies have examined the validity of the SBI, the validity of the selfwarmth and control composite scores is supported by the following findings from the present study: (a) the self-warmth score was correlated with the biological parent's and stepchild's ratings of the stepfather's warmth parenting behaviors (rs = .62 and .51, respectively, ps [is less than] .01); (b) the self-warmth score was correlated with the stepfather's rating of how often he or she engaged in behaviors aimed at eliciting liking from the stepchild ( $\mathrm{r}=.86$, $\mathrm{p}$ [is less than] .01), a construct that is conceptually similar to warmth; (c) the self-control score was correlated with the 
biological parent's and stepchild's ratings of the stepfather's control parenting behaviors, $(\mathrm{rs}=.30$ and .35, respectively, ps [is less than] .05); and (d) the self-warmth score was more strongly correlated with the biological parent's and stepchild's ratings of the stepfather's warmth behaviors than with their ratings of the stepfather's control parenting behaviors. The self-control score was more strongly correlated with the biological parent's and stepchild's ratings of the stepfather's control behaviors than with their ratings of the stepfather's warmth parenting behaviors (providing evidence for discriminant validity).

Four composite role-discrepancy scores were computed from these subscales of the SBI. First, a self-ideal warmth discrepancy score was computed as the mean of the absolute values of the differences between each warmth item on the self and ideal versions of the instrument. Second, a self-ideal control discrepancy score was computed as the mean of the absolute values of the differences between each control item on the self and ideal versions of the instrument. Third, a self-ought warmth discrepancy score was computed as the mean of the absolute values of the differences between each warmth item of the self and ought versions of the instrument. Fourth, a self-ought control discrepancy score was computed as the mean of the absolute values of the differences between each control item of the self and ought versions of the instrument. Absolute values were used because differences in either direction were considered to theoretically have similar meanings (Higgins, 1987); in other words, engaging in behaviors either less often or more often than one thinks one should is thought to evoke similar negative emotions. However, because a case-by-case analysis revealed that, for almost all participants, discrepancies were due to self scores being lower than ideal or ought scores, the results were virtually identical when absolute and nonabsolute discrepancy scores were used. Cronbach's alphas for the self-ideal warmth and control and self-ought warmth and control discrepancy scores were .74, .75, .71, and .66 , respectively.

In the absence of an established measure, role clarity was assessed by the Stepparent Role Inventory, an 8-item instrument developed for this study. On each item (e.g., "I often wonder if I am being a good stepfather" [reverse-coded], "I know how to be a good stepfather"), respondents rated their level of agreement on a 1 (strongly disagree) to 7 (strongly agree) Likert-type scale. Cronbach's alpha was .79.

Dejection-related emotions and satisfaction. Dejection-related emotions were conceptualized not only as depression but (consistent with Higgins, 1987) also as satisfaction. A number of dimensions of satisfaction were assessed: satisfaction with one's experience as a stepparent, life satisfaction, marital satisfaction, and perceived family strengths. Because satisfaction with being a stepparent is likely to be linked to stepparent involvement, perceived success as a stepfather, and perceived closeness with the stepchild, these variables were also included in this category.

Depression was measured by a subscale of the 53-item Brief Symptom Checklist (Derogatis, 1993). On each item, participants rated whether they experienced the symptom not at all (0), a little bit (1), moderately (2), quite a bit (3), or extremely (4) in the last week. Items on the 6-item 
depression scale include "feeling blue" and "feeling hopeless about the future." Cronbach's alpha in this sample was .69.

Satisfaction with stepparenting experiences was measured by 12 items, 6 of which (E205AE205F) were chosen from the National Survey of Families and Households (Sweet et al., 1988). The items were written in a semantic differential format (e.g., "easy" vs. "difficult," "boring" vs. "interesting") and participants rated their experiences on a 1 to 7 Likert-type scale. Responses were coded so that higher scores were indicative of greater satisfaction. Cronbach's alpha was .87.

To measure life satisfaction, the 5-item Satisfaction With Life Survey (Diener, Emmons, Larsen, \& Griffin, 1985) was administered. On each item (e.g., "I am satisfied with my life."), respondents rated their level of agreement on a 1 (strongly disagree) to 7 (strongly agree) Likerttype scale. Cronbach's alpha was .85.

Marital satisfaction was assessed by the 3-item Kansas Marital Satisfaction Scale (Schumm et al., 1986). On each question (e.g., "How satisfied are you with your marriage?"), participants rated their level of satisfaction on a 1 (extremely dissatisfied) to 7 (extremely satisfied) Likerttype scale. Cronbach's alpha was .89.

Perceived family strengths were measured by the 12-item Family Strengths Scale (Olson, Larsen, \& McCubbin, 1982). On each item (e.g., "Family members feel loyal to the family." "We really do trust and confide in each other."), respondents rated their level of agreement on a 1 (strongly disagree) to 7 (strongly agree) Likert-type scale. Cronbach's alpha was .84.

Stepparent involvement was assessed by a modified version of the Family Involvement Scale (Yogev \& Brett, 1985). The instrument was modified so that stepfathers were asked to rate the extent of their involvement as a stepparent and with their stepfamily. On each of the 7 items (e.g., "I am very much involved personally with my stepfamily members' lives," "I enjoy talking about my stepfamily with other people."), respondents rated their level of agreement on a 1 (strongly disagree) to 7 (strongly agree) Likert-type scale. Cronbach's alpha was .75.

Perceived success as a stepfather was assessed by one item that asked respondents, "How successful do you think you've been as a stepfather?" on a 1 (not at all) to 7 (very much) Likerttype scale.

Closeness with stepchild was measured by one item that asked participants, on a 1 (not at all close) to 5 (extremely close) Likert-type scale, "In the last 6 weeks, how close has your relationship to your stepchildren been?"

Agitation-related emotions. Anxiety was assessed by the 6-item Anxiety subscale of the Brief Symptom Inventory (BSI). Sample items include "nervousness or shakiness inside" and "feeling tense or keyed up." Despite the low Cronbach's alpha of .58 in this sample, we included this 
subscale because its psychometric properties have been supported in previous research (Derogatis, 1993).

Shame pertaining to the stepparent role was assessed by a 10-item instrument developed for this study. On each item (e.g., "I am embarrassed about the job I do as a stepfather." "I am ashamed to talk to others about how I feel about being a stepfather."), participants rated their level of agreement on a 1 (strongly disagree) to 7 (strongly agree) Likert-type scale. Cronbach's alpha was .81.

\section{RESULTS}

Preliminary analyses. To determine whether any of the demographic and/or marital history variables should be employed as covariates in subsequent analyses, Pearson correlations were computed between each of the demographic and marital history variables and the dependent and independent variables. Fewer than $5 \%$ of these correlations were significant, suggesting that there would be no utility in using any of these variables as covariates.

Description of stepfathers on dependent and independent variables. Means and standard deviations on all measures used in this study are presented in Table 1. For comparative purposes, the table also shows available norms on the instruments. On the instruments for which norms are available, the present sample had scores that were generally similar to those from the respective normative groups.

TABLE 1

Means and Standard Deviations on

Independent and Dependent Variables

M

Independent variables

Self-warmth

Self-control

Ideal warmth

Ideal control

ought warmth

ought control

Self-ideal warmth discrepancy

Self-ideal control discrepancy

Self-ought warmth discrepancy

Self-ought control discrepancy

Role clarity

$\begin{array}{rl}4.93 & .89 \\ 5.39 & .94 \\ 5.75 & .70 \\ 5.99 & .73 \\ 5.82 & .76 \\ 5.95 & .75 \\ 1.06 & .56 \\ .80 & .56 \\ 1.24 & .58 \\ 1.16 & .53 \\ 4.44 & .93\end{array}$

Dependent variables

BSI depression(a)

Stepparent involvement(b)

$.21 \quad .28$

$5.14 \quad .84$

$3.16 \quad .92$ 


\begin{tabular}{|c|c|c|}
\hline Satisfaction with life(c) & 4.93 & 1.06 \\
\hline Perceived success as a stepfather & 5.21 & 1.26 \\
\hline Closeness with stepchild & 3.23 & .99 \\
\hline Kansas Marital Satisfaction Scale(d) & 6.00 & .81 \\
\hline Family strength(e) & 5.10 & .77 \\
\hline BSI anxiety(a) & .28 & .30 \\
\hline \multirow[t]{2}{*}{ Stepparent shame } & 2.62 & .88 \\
\hline & Norm & $(\mathrm{SD})$ \\
\hline \multicolumn{3}{|l|}{ Independent variables } \\
\hline Self-warmth & -- & \\
\hline Self-control & -- & \\
\hline Ideal warmth & -- & \\
\hline Ideal control & -- & \\
\hline Ought warmth & -- & \\
\hline Ought control & -- & \\
\hline Self-ideal warmth discrepancy & -- & \\
\hline Self-ideal control discrepancy & -- & \\
\hline Self-ought warmth discrepancy & -- & \\
\hline Self-ought control discrepancy & -- & \\
\hline Role clarity & -- & \\
\hline \multicolumn{3}{|l|}{ Dependent variables } \\
\hline BSI depression(a) & .21 & $(.33)$ \\
\hline Stepparent involvement(b) & 5.45 & $(.72)$ \\
\hline Satisfaction with stepparent experience & -- & \\
\hline Satisfaction with life(c) & 4.70 & \\
\hline Perceived success as a stepfather & -- & \\
\hline Closeness with stepchild & -- & \\
\hline Kansas Marital Satisfaction Scale(d) & 6.09 & $(.86)$ \\
\hline Family strength(e) & 5.32 & $(.75)$ \\
\hline BSI anxiety $(a)$ & .26 & $(.31)$ \\
\hline Stepparent shame & -- & \\
\hline
\end{tabular}

NOTE: BSI = Brief Symptom Inventory.

(a.) From Derogatis's (1993) norms for adult nonpatient males.

(b.) Norms calculated from Yogev and Brett's (1985) data on men.

(c.) From Diener, Emmons, Larsen, and Griffin's (1985) norms for undergraduates.

(d.) Norms are from Schumm et al. (1986) data.

(e.) Norms are from Olson, Larsen, and McCubbin's (1982) data on men. 
Although caution must be exercised when drawing inferences from mean scores when there are no existing norms, it is noteworthy that the stepfathers in this sample had relatively high scores (item means above 4.9 on a 1 to 7 Likert-type scale) on the self, ideal, and ought warmth and control subscales and midrange scores on the role clarity measure (a mean just above the theoretical midpoint of the 1 to 7 Likert-type scale). Further, these stepfathers had relatively high scores on stepparent involvement and perceived success as a stepfather (means above 5 on the 1 to 7 Likert-type scale) and low scores on stepparent shame (a mean below 3 on the 1 to 7 Likerttype scale).

Relations between role perceptions and stepfather adjustment. To determine the relations between stepfathers' role perceptions and the adjustment dimensions, Pearson correlations were computed between the self, ideal, and ought warmth and control composite scores and the dependent variables. The correlations are presented in Table 2.

TABLE 2

Pearson Correlations Between Role Perceptions and Adjustment Scores

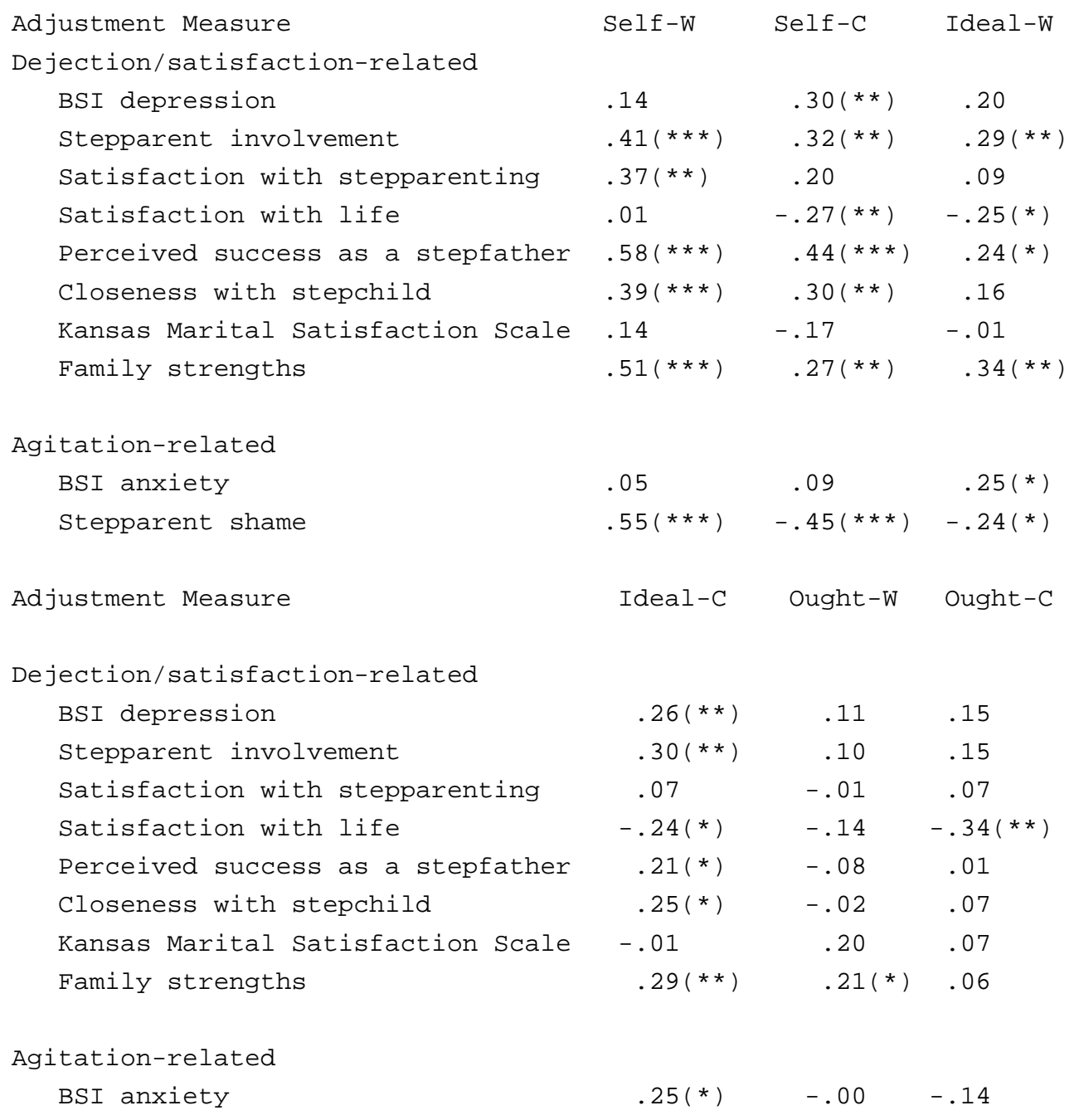


NOTE: Self, Ideal, and Ought scales assess how frequently stepfathers believe that they engage in parenting behaviors, how often they believe that they should engage in these behaviors, and how often they think others think that they should engage in these behaviors, respectively BSI = Brief Symptom Inventory; $\mathrm{W}=$ Warmth subscale; $\mathrm{C}=$ Control subscale.

$(*) \mathrm{p}<.10$.

$(* *) \mathrm{p}<.05$.

$(* * *) \mathrm{p}<.01$

As shown in the table, stepfathers' perceptions of how often they engage in parenting behaviors (self scores) were positively related to their involvement as a stepparent, satisfaction with their experience as stepparents (on warmth only), perceived success as a stepfather, perceived closeness with their stepchild, and perceived family strengths. In addition, stepfathers' perceptions of the frequency with which they engage in warmth and control parenting behaviors were negatively related to stepparent shame.

Stepfathers' standards for how often they should engage in these parenting behaviors (ideal scores) were positively related to depression (on control only), stepparent involvement, perceived success as a stepparent, perceived closeness with stepchild (on control only), and perceived family strengths, and negatively related to life satisfaction and stepparent shame (on warmth only).

Stepfathers' beliefs of how often others think that they should engage in these parenting behaviors (ought scores) were positively related to family strengths (on warmth only) and negatively related to life satisfaction (on control only).

In general, the pattern was that stepfathers who reported that they frequently engage in warmth and control parenting behaviors and who believed that they should frequently engage in these behaviors reported better adjustment on dimensions related to their stepparent experience. These perceptions were less strongly related to the more intrapersonal dimensions of adjustment, including depression, anxiety, and life satisfaction, although depression and life satisfaction were negatively related to how often stepfathers reported that they engaged in control parenting behaviors and how often they should engage in these behaviors.

Relations between role discrepancies and stepfather adjustment. Pearson correlations were computed between the four role discrepancy scores--self-ideal and self-ought warmth and control scores and each of the dependent variables. The results are presented in Table 3.

TABLE 3

Pearson Correlations Between Role Discrepancy and Clarity and 


\begin{tabular}{|c|c|c|}
\hline Adjustment measure & $S-I-W$ & $\mathrm{~S}-\mathrm{I}-\mathrm{C}$ \\
\hline \multicolumn{3}{|l|}{ Dejection/satisfaction-related } \\
\hline BSI depression & .02 & -.12 \\
\hline Stepparent involvement & $-.27(* *)$ & $-.28(* *)$ \\
\hline Satisfaction with stepparenting & $-.47(* * *)$ & $-.30(* *)$ \\
\hline Satisfaction with life & $-.36(* *)$ & .04 \\
\hline Perceived success as a stepfather & $-.50(* * *)$ & $-.41(* * *)$ \\
\hline Closeness with stepchild & $-.31(* *)$ & $-.24\left({ }^{*}\right)$ \\
\hline Kansas Marital Satisfaction Scale & $-.36(* *)$ & -.16 \\
\hline Family strengths & $-.46(* *)$ & $-.24\left({ }^{*}\right)$ \\
\hline \multicolumn{3}{|l|}{ Agitation-related } \\
\hline BSI anxiety & .17 & $.23(*)$ \\
\hline Stepparent shame & $.47(* \star *)$ & $.57(* * *)$ \\
\hline Adjustment measure & $S-0-W$ & S-0-C \\
\hline \multicolumn{3}{|l|}{ Dejection/satisfaction-related } \\
\hline BSI depression & -.01 & -.11 \\
\hline Stepparent involvement & $-.27(* *)$ & $-.30(* *)$ \\
\hline Satisfaction with stepparenting & $-.43(* * *)$ & $-.21(*)$ \\
\hline Satisfaction with life & -.18 & .13 \\
\hline Perceived success as a stepfather & $-.49(* * *)$ & -.09 \\
\hline Closeness with stepchild & $-.31(* *)$ & -.20 \\
\hline Kansas Marital Satisfaction Scale & $-.25\left({ }^{*}\right)$ & -.15 \\
\hline Family strengths & $-.41(* * *)$ & -.20 \\
\hline \multicolumn{3}{|l|}{ Agitation-related } \\
\hline BSI anxiety &.$- \odot \odot$ & -.19 \\
\hline Stepparent sham & $.50(* * *)$ & $.46(* * *)$ \\
\hline Adjustment measure & Role clarity & \\
\hline \multicolumn{3}{|l|}{ Dejection/satisfaction-related } \\
\hline BSI depression & -.09 & \\
\hline Stepparent involvement & $.49(* * *)$ & \\
\hline Satisfaction with stepparenting & $.63(* * *)$ & \\
\hline Satisfaction with life & .01 & \\
\hline Perceived success as a stepfather & $.49(* * *)$ & \\
\hline Closeness with stepchild & $.24\left({ }^{*}\right)$ & \\
\hline Kansas Marital Satisfaction Scale & $.23\left({ }^{*}\right)$ & \\
\hline Family strengths & $.57(* * *)$ & \\
\hline \multicolumn{3}{|l|}{ Agitation-related } \\
\hline BSI anxiety & -.11 & \\
\hline
\end{tabular}


NOTE: BSI = Brief Symptom Inventory. S-I-W = self-ideal warmth discrepancy score; S-1-C = self-ideal control discrepancy score; S-O-W = self-ought warmth discrepancy score; $\mathrm{S}-\mathrm{O}-\mathrm{C}=$ self-ought control discrepancy score.

$(*) \mathrm{p}<.10$.

$(* *) \mathrm{p}<.05$.

$(* * *) \mathrm{p}<.01$.

As shown in the table, several patterns emerged from the correlations. First, role discrepancy scores were significantly correlated with stepfamily involvement, satisfaction with one's experience as a stepparent, satisfaction with life (only on the self-ideal warmth discrepancy score), perceived success as a stepfather (except on the self-ought control discrepancy score), perceived closeness with stepchild (except on the self-ought control discrepancy score), marital satisfaction (only on the warmth discrepancy scores), perceived family strengths (except on the self-ought control discrepancy score), and stepparent shame. As hypothesized, small discrepancies were related to more stepfamily involvement, more satisfaction with experiences as a stepparent, greater satisfaction with life, greater perceived success as a stepfather, greater perceived closeness with the stepchild, more marital satisfaction, more perceived family strengths, and less stepparent shame.

Second, as expected, discrepancies on the warmth parenting dimension were more often significantly correlated with the adjustment measures than were discrepancies on the control parenting dimension. Further, the magnitude of the correlations with the adjustment measures were generally greater for the warmth discrepancy scores than for the control discrepancy scores.

Third, only one correlation involving the depression and anxiety scores--the most intrapersonal of the adjustment measures--was significant: Anxiety was positively related to the self-ideal control discrepancy score.

Relations between role clarity and stepfather adjustment. Table 3 also shows the Pearson correlations between the role clarity score and each of the adjustment scores. As hypothesized, greater role clarity was related to more stepfamily involvement, more satisfaction with experiences as a stepparent, greater perceived success as a stepfather, greater perceived closeness with the stepchild, more marital satisfaction, more perceived family strengths, and less stepparent shame.

\section{DISCUSSION}


Our findings suggest that a number of aspects of how stepfathers construct their roles are related to their adjustment. Particularly salient for positive outcomes were (a) stepfathers' perceptions that they frequently engage in and should frequently engage in parenting behaviors; (b) small discrepancies between perceived role behavior and personal standards of how to behave as a stepparent (self-ideal) and between perceived role behavior and perceptions of how others think that stepfathers should behave (self-ought), particularly with respect to the warmth parenting dimension; and (c) role clarity.

The relation between role perceptions and stepfather adjustment. Generally, stepfathers were more satisfied with a number of dimensions of their marital and family lives when they perceived that they frequently engage in authoritative parenting behaviors (i.e., they engage in both warmth and control behaviors toward their stepchildren). At least from the stepfathers' perspective, our findings do not support claims made that stepparents should not actively engage in disciplining their stepchildren (Bray \& Berger, 1993; Hetherington, 1993). In our study, stepfathers who reported being more active parents also expressed more satisfaction with several dimensions of their family lives. From a symbolic interaction framework, these findings suggest that stepparents who construct the stepparent role (derived from experiences in the stepfamily) as an active one perceive themselves to be more satisfied with the role, and with stepfamily life as a whole. However, a caveat is in order because these perceptions that one is and should be an active parent on the control dimension come with an apparent cost--potentially higher levels of depression.

Because length of time in the stepfamily was not related to any of the role perception and adjustment variables, there was no evidence that the nature of the relation between stepfathering behavior and adjustment changes over the life course of the stepfamily. However, this finding should be viewed with caution because limited variability on the length of time in the stepfamily variable in this sample may have attenuated the magnitude of the correlation coefficients.

From our correlational design, we cannot infer that stepfathers' perceptions of their parenting behaviors lead to better adjustment. It is also possible that stepfathers who are better adjusted (or perceive themselves to be) are more likely to perceive that they take an active role as a stepparent.

Our results also suggest that personal standards about parenting are important correlates of stepfather adjustment. In this study, stepfathers who believed that they should actively show warmth and control toward their stepchildren reported being more satisfied with several aspects of their marital and family lives. In particular, standards that they should actively parent were related to stepparent involvement, perceived success as a stepfather, perceived closeness with stepchild, perceived family strengths, and a lack of shame as a stepparent. Again, it is not possible to tease apart the causal nature of the relation between these standards and adjustment; it is possible that stepparents who believe that they should actively parent behave in ways that bring them greater satisfaction from their stepfamily experiences or that those stepparents who 
have positive stepfamily experiences, because contact with their stepchildren is pleasant, come to believe that they should be active as parents.

These results--that stepparents who report that they actively engage in and should engage in control parenting behaviors toward their stepchildren are more satisfied with some aspects of their stepfamily lives than those who do not--seems incongruent with the commonly given clinicians' advice that stepparents should let the biological parents take the lead in disciplining stepchildren, at least in the early years of the stepfamily (Visher \& Visher, 1996). Stepparents are generally advised by clinicians to focus on developing warm, positive relationships with stepchildren before assuming an active disciplinary role.

To reconcile our results with this prevailing clinical advice, three points should be considered. First, it is possible that the satisfaction and adjustment of stepchildren, and perhaps of mothers as well, are inversely related to how actively the stepfather engages in disciplinary (control) parenting behaviors. The unit of analysis in the data used in this article was the individual stepfather, rather than other individuals or dyads within the family system. Therefore, results pertaining to stepfathers may not generalize to other stepfamily members. Second, given the cross-sectional nature of these data, it is not possible for us to determine the temporal sequencing of when stepfathers began engaging in warmth and control parenting behaviors; they may have emphasized the warmth dimension of parenting initially, as clinicians advise, or they may have engaged in warmth and control parenting behaviors concurrently during the life of the relationship, or they may even have disciplined children initially, and then utilized more relationship-developing behaviors (i.e., warmth) later. This issue needs to be examined in future longitudinal efforts. Third, as noted earlier, there may be an intrapsychic cost associated with being a more active parent and believing that one should be a more active parent--greater levels of depression and anxiety, and less life satisfaction. Thus, although construing the stepparent role as an active one may lead to more satisfying stepfamily experiences, it may also lead to some emotional distress. In this respect, our findings are consistent with the prevailing clinical advice noted earlier (Visher \& Visher, 1996).

By contrast, beliefs pertaining to how actively others think the stepparent should parent were generally unrelated to the adjustment dimensions. Apparently, personal standards are more salient to stepfathers' adjustment than are their perceptions of others' standards.

The relations between stepparent role discrepancies and stepfather adjustment. Low scores on the role, discrepancy variables (self-ideal and self-ought), particularly on the warmth dimension of parenting, were related to stepfathers' involvement, satisfaction with the stepfamily experience, perceived success as a stepfather, perceived closeness with stepchild, marital satisfaction, perceived family strengths, and stepparent shame (negatively related). Contrary to our expectation, the role discrepancy scores were generally not related to stepfathers' reports of depression, anxiety, and life satisfaction. 
In one sense, these findings support the tenets of Higgins's (1987) self-discrepancy theory: Greater discrepancies were associated with less satisfaction and more shame. However, inconsistent with the theory, self-ideal discrepancies were not uniquely related to dejectionrelated emotions/satisfaction and self-ought discrepancies were not uniquely related to agitationrelated emotions. Rather, both types of discrepancies were related in similar ways to all of the adjustment measures. The two types of discrepancy scores were highly correlated $(r=.86$ between the self-ideal warmth and self-ought warmth discrepancy scores and $r=.53$ between the self-ideal control and self-ought control discrepancy scores, ps [is less than] .01), suggesting either that the stepfathers discriminated only moderately between their own standards and their perceptions of others' standards for their behavior as stepparents or that our measures were not sensitive to this distinction. If the latter explanation is correct, it may be helpful in future research to construct a measure of perceptions of a specific target's standards (e.g., my spouse, my best friend, my parents), particularly a significant other, rather than the generic "other" that was used in the present study.

Similar to the findings of Fine and Kurdek (1994), our results suggest that role discrepancies pertaining to the warmth dimension of parenting were more strongly related to stepfathers' adjustment than were discrepancies related to the control dimension of parenting. To explain this pattern, three interrelated possible explanations are posited. First, perhaps the warmth dimension of parenting is more salient (i.e., more central to one's self-image) to stepfathers than is the control dimension. If this is the case, perceived behavioral deviations from one's standards on the warmth dimension would more strongly affect adjustment than would deviations on the control dimension. Second, perhaps warmth is perceived by stepfathers as a uniformly positive behavior to exhibit, whereby there is more ambivalence and uncertainty about the control dimension of parenting (Fine \& Kurdek, 1994). In particular, moderate levels of control may be regarded by parents as more desirable than excessively low or high levels. Thus, deviations between perceived role performance and standards on the warmth parenting dimension may be particularly disruptive to adjustment because warmth is perceived as an unvarying ideal way to behave toward children. Third, one would expect that warmth, as a positive interpersonal construct, would be more strongly related than control to adjustment dimensions involving the quality of interpersonal relationships (e.g., closeness to the stepchild, marital satisfaction, family strengths).

In explaining why role discrepancies (and role clarity) were not generally related to the most intrapersonal of the adjustment dimensions assessed (i.e., depression, anxiety, life satisfaction), it may be helpful to reiterate one feature of Higgins's (1987) self-discrepancy theory. According to Higgins, discrepancies invoke negative emotions only when these discrepancies are activated, meaning that the discrepancy is salient in a particular context (i.e., it has been contextually primed). In this study, discrepancies were assessed only in relation to the stepparent role; a variety of other possible self-discrepancies, such as those pertaining to self-concept (see Schafer, Wickrama, \& Keith, 1996) were not assessed. One would expect that stepparent role 
discrepancies would most likely be activated when stepfathers am asked to rate dimensions of their well-being that are particularly salient to the stepparent role (i.e., satisfaction with stepparenting experiences, stepparent involvement, perceived success as a stepfather, perceived closeness with stepchild, and stepparent shame) and would be less likely to be activated when stepfathers rate aspects of their individual well-being (e.g., life satisfaction, depression, and anxiety).

Thus, these findings suggest that self-discrepancies, at least in the stepfather family context, have their greatest influence on dimensions of well-being that are proximal to the discrepancy being assessed. Further, these discrepancies appear to have lesser effects on dimensions that are more distal. to the discrepancy domain assessed. These suppositions are consistent with Burke's (1991) identity process model, in which it is argued that discrepancies between one's own self-concept and others' view of oneself will lead to greatest distress when the source of the perceived discrepancy is a significant other (i.e., a significant other may be considered more proximal than are less salient individuals).

To some extent, these discrepancies reflect self-perceptions of inadequate role performance. Thus, to the extent that stepfathers come to believe that they are inadequately fulfilling their stepparent role, lesser marital and family well-being results. We posit that this process is related to why stepfathers come to believe that their role performance is inadequate. For example, one plausible scenario is that some stepfathers' spouses or stepchild(ren) may interfere with their preferred role enactment, which may lower relationship evaluations. Another plausible scenario is that some stepfathers have unrealistically high standards for how actively they should parent, which ultimately leads to less satisfying stepfamily experiences and poorer quality stepfamily relationships.

The relation between role clarity and stepfather adjustment. Findings with respect to role clarity-that role clarity is related to more positive adjustment--provide empirical support for claims made in the theoretical and clinical literatures that stepparent role clarity is a critical factor in how stepparents adjust in stepfamilies (Crosbie-Burnett, 1989; Visher \& Visher, 1988, 1996). These results also replicate and extend Kurdek and Fine's (1991) finding that stepfathers' role clarity was positively related to satisfaction with stepparenting by showing that role clarity is related to a larger number of marital- and stepfamily-related adjustment dimensions.

Limitations and implications for future research. Several limitations need to be taken into account when considering the present findings. First, the sample was nonrandomly recruited and was of only moderate size. In addition, our comparison of the present sample with a large, nationally representative sample suggested that our stepfathers were somewhat older, better educated, and in longer-lasting stepfamilies than is the population of stepfathers. Thus, our findings need to be interpreted with caution because they may not generalize to stepfathers in generaL However, our concerns in this area were allayed to some extent because the sample scored similarly to normative samples (when they were available) on standardized instruments. 
Nevertheless, we recommend that future studies employ randomly selected and larger samples if possible.

Second, because all of the data reported in this study were gathered from stepfathers, it is possible that common method variance accounted for some of the observed relations. However, the finding that discrepancy scores, which are less vulnerable to social desirability biases than are the constituent scores from which they are derived, were related to self-reported adjustment addresses,this concern to some extent. Future studies might consider assessing the relations between stepparents' role constructions and others' perceptions of stepfathers' adjustment (which were not assessed in the larger study).

Third, some of the measures employed were, by necessity, developed for this study. Thus, their psychometric properties were untested before this study. However, reducing this concern to some extent, all of the multi-item composite scores developed for this study were internally consistent. Nevertheless, future studies that assess the psychometric properties of these measures are needed.

\section{REFERENCES}

Alexander, M. J., \& Higgins, E. T. (1993). Emotional trade-offs of becoming a parent: How social roles influence self-discrepancy effects. Journal of Personality and Social Psychology, 65, 1259-1269.

Bray, J. H., \& Berger, S. H. (1993). Developmental issues in step families research project: Family relationships and parent-child interactions. Journal of Family Psychology, 7, 76-90.

Burke, P. J. (1991). Identity processes and social stress. American Sociological Review, 56, 836849.

Crosbie-Burnett, M. (1989). Application of family saws theory to remarriage: A model for assessing and helping stepfamilies. Family Relations, 38, 323-331.

Derogatis, L R. (1993). Brief symptom inventory: Administration, scoring, and procedures manual. Minneapolis, MN: National Computer Systems.

Diener, E., Emmons, R. A., Larsen, R. J., \& Griffin, S. (1985). The satisfaction with life scale. Journal of Personality Assessment, 49, 71-75.

Feldman, S. S., \& Weinberger, D. A. (1994). Self-restraint as a mediator of family influences on boys' delinquent behavior: A longitudinal study. Child Development, 65, 195-211.

Fine, M. A., \& Kurdek, L A. (1994). Parenting cognitions in stepfamilies: Differences between parents and stepparents and relations to parenting satisfaction. Journal of Social and Personal Relationships, 11, 95-112. 
Hetherington, E. M. (1993). An overview of the Virginia Longitudinal Study of Divorce and Remarriage with a focus on early adolescence. Journal of Family Psychology, 7, 39-56.

Higgins, E. T. (1987). Self-discrepancy: A theory relating self and affect. Psychological Review, 94, 319-340.

Higgins, E. T, Klein, R., \& Strauman, T (1985). Self-concept discrepancy theory: A psychological model for distinguishing among different aspects of depression and anxiety. Social Cognition, 3, 51-76.

Kurdek, L. A., \& Fine, M. A. (1991). Cognitive correlates of adjustment for mothers and stepfathers in stepfather families. Journal of Marriage and the Family, 53, 565-572.

Lamborn, S. D., Mounts, N. S., Steinberg, L., \& Dornbusch, S. M. (1991). Patterns of competence and adjustment among adolescents from authoritative authoritarian indulgent and neglectful families. Child Development, 62, 1049-1065.

LaRossa, R., \& Reitzes, D. C. (1993). Symbolic interactionism and family studies. In P. G. Boss, W. J. Doherty, R. LaRossa, W. R. Schumm, \& S. K. Steinmetz, (Eds.), Sourcebook of family theories and methods: A conceptual approach (pp. 135-163). New York: Plenum.

Maccoby, E. M., \& Martin, J. (1983). Socialization in the context of the family: Parent-child interaction. in E. M. Hetherington (Ed.), P. H. Mussen (series Ed.), Handbook of child psychology Vol. 4: Socialization, personality and social development. New York: John Wiley.

Marsiglio, W. (1992). Stepfathers; with minor children living at home: Parenting perceptions and relationship quality. Journal of Family Issues, 13, 195-214.

Olson, D. H., Larsen, A. S., \& McCubbin, H. I. (1982). Family strengths. In D. H. Olson, H. I. McCubbin, H. Barnes, A. Larsen., M. Muxen, \& M. Wilson (Eds.), Family inventories: Inventories used in a national survey of families across the family life cycle (pp. 121-134). St. Paul: University of Minnesota, Department of Family Social Science.

Rodgers, R. H., \& White, J. M. (1993). Family development theory. In P. G. Boss, W. J. Doherty R. LaRossa, W. R. Schumm, \& S. K. Steinmetz (Eds.), Sourcebook of family theories and methods: A conceptual approach (pp. 225-254). New York: Plenum.

Schafer. R. B., Wickrama, K.A.S., \& Keith. P. M. (1996). Self-concept disconfirmation, psychological distress, and marital happiness. Journal of Marriage and the Family, 58, 167-177.

Schumm W. R., Paff-Bergen, L. A., Hatch, R. C., Obiorah, F. C., Copeland, J. M. Meens, L. D., \& Bugaighis, M. A. (1986). Concurrent and discriminant validity of the Kansas Marital Satisfaction Scale. Journal of Marriage and the Family, 48, 381-387. 
Steinberg, L, Dornbusch, S. M., \& Brown, B. B. (1992). Ethnic differences in adolescent achievement An ecological perspective. The American Psychologist, 47, 723-729.

Strauman, T. J., \& Higgins, E. T. (1987). Automatic activation of self-discrepancies and emotional syndromes: When cognitive structures influence affect. Journal of Personality and Social Psychology, 53, 1004-1114.

Stryker, S., \& Statham A. (1985). Symbolic interaction and role theory. In G. Lindzey \& E. Aronson (Eds.), The handbook of social psychology (Vol. 1) (pp. 311-378). New York: Random Home.

Sweet, J. A., Bumpass, L. L., \& Call, V.R.A. (1988). The design and content of the National Survey of Families and Household (Working Paper NSFH-1). Madison: University of Wisconsin, Center for Demography and Ecology.

Visher, FL, \& Visher J. S. (1988). Old loyalties, new ties. New York: Brunner/Mazel.

Visher, E. B., \& Visher, J. S. (1996). Therapy with stepfamilies. New York: Brunner/Mazel.

Watson, D., \& Kendall, P. C. (1989). Understanding anxiety and depression: Their relation to negative and positive affective states. In P. C. Kendall \& D. Watson (Eds.), Anxiety and depression: Distinctive and overlapping features (pp. 3-26). San Diego, CA: Academic Press.

Yogev, S., \& Brett, J. (1985). Patterns of work and family involvement among single- and dualearner couples. Journal of Applied Psychology, 70, 754-768.

Authors' Note: This work was partially supported by a grant from the University of MissouriColumbia Research Council. The authors express appreciation to Larry Kurdek for his valuable input into the study. Please address correspondence to Mark A. Fine, Department of Human Development and Family Studies, University of Missouri, 31 Stanley Hall, Columbia MO 65211; e-mail: hdfsfine@showme.missouri.edu. 